OPEN ACCESS

Edited by:

Osman Titrek

Sakarya University, Turkey

Reviewed by:

Dongyoup Kim,

Gachon University, South Korea

Umar Farooq Sahibzada,

Northwestern Polytechnical

University, China

${ }^{*}$ Correspondence:

Marijana Oljaca

makica_sa@yahoo.com

Saba Fazal Firdous

sabafazalfirdousi@gmail.com

Specialty section:

This article was submitted to

Organizational Psychology,

a section of the journal

Frontiers in Psychology

Received: 30 June 2021 Accepted: 06 September 2021

Published: 12 October 2021

Citation:

Li Z, Oljaca M, Firdousi SF and Akram $U$ (2021) Managing Diversity in the Chinese Organizational Context:

The Impact of Workforce Diversity

Management on Employee Job

Performance.

Front. Psychol. 12:733429.

doi: 10.3389/fpsyg.2021.733429

\section{Managing Diversity in the Chinese Organizational Context: The Impact of Workforce Diversity Management on Employee Job Performance}

\author{
Zhiwen $\mathrm{Li}^{1}$, Marijana Oljaca ${ }^{1 *}$, Saba Fazal Firdousi ${ }^{2 \star}$ and Umair Akram ${ }^{1}$ \\ ${ }^{1}$ School of Management, Jiangsu University, Zheniiang, China, ${ }^{2}$ Lahore School of Economics, Lahore, Pakistan
}

The purpose of this study is to investigate the impact of workforce diversity management on employee job performance in the Chinese organizational context, considering the mediating effect of person-job match and employee commitment and the moderating effect of structural empowerment. Data were collected from 400 telecommunication sector employees in China. All hypotheses were tested through structural equation modeling (SEM). The findings of the study illustrated that workforce diversity management has a positive and significant impact on employee job performance. Furthermore, the results indicated that person-job match and employee commitment partially mediate the relationship between workforce diversity management and employee job performance. Moreover, structural empowerment directly affects employee job performance, whereas a moderating effect is also found in the relationship between workforce diversity management and employee job performance. Finally, implications and limitations are discussed.

Keywords: workforce diversity management, employee job performance, person-job match, employee commitment, structural empowerment, telecommunication sector, China

\section{INTRODUCTION}

In recent decades, workforce diversity has been considered to play an important role in organizations. Because organizations aim to create positive awareness and working environments for the hired professional workforce and develop fundamental skills to address job-related problems (Mor Barak, 2015), many management levels consider that they have a moral duty to promote equality and likeness in the organization (Mor Barak et al., 2016; Li et al., 2020c). Workforce diversity management is related to resolving employee job issues associated with fairness, justice, and equality based on employee age, gender, ethnicity, and education (Ng and Sears, 2012), as well as other job-related issues such as unsuitable jobs and undesirable job responsibilities (Joshi and Jackson, 2003; Bassett-Jones, 2005).

Based on broad perspectives, many studies have investigated how workforce diversity management relates to organizational performance (Bunderson and Sutcliffe, 2002; Prieto et al., 2009). Some scholars have shown that effective fairness and equality created by workforce diversity management lead to a high level of employee performance (Casper et al., 2013; Ju and Li, 2019; Moon and Christensen, 2020). However, others have reported an insignificant impact of workforce diversity management on firm and employee performance (Horwitz and Horwitz, 2007; Li et al., 2017). These inconclusive results indicate the need for further research on the workforce diversity management and job 
performance link. First, elaborating the underlying processes (i.e., mediators and moderators) of the link is crucial; second, investigations of its role in different contexts can further enrich the picture. This empirical study provides solid evidence of the underlying process by which workforce diversity management shapes employee job performance in the Chinese organizational context.

Previous studies suggest that there is a need to explore intermediary factors between workforce diversity management and employee job performance. Based on the existing literature, the link between diversity management and organization performance, as well as related employee job satisfaction, has been well-explored, particularly in organizational and behavioral psychology (Choi and Rainey, 2010). Job satisfaction is associated with the actual evaluation of work of an employee in an organization, and firm performance refers to a set of job activities performed by employees to better the organization (Cooke and Saini, 2010). Previous studies have noted that person (education) and job matches led by workforce diversity have become important issues in the working environment of today (Luu et al., 2019) because person-job mismatches can negatively influence employee performance (Maden, 2014). A study conducted in America using a sample of 200 employees revealed that $29.5 \%$ of employees had experienced discrimination in their workplace because of irrelevant job assignments, job tasks, and duties as well as job engagement and an unsuitable working environment ( $\mathrm{Li}$ et al., 2017). According to Li et al. (2020c), the person-job match refers to the correspondence between the employment of an individual and his and her education and experience. Employees must be satisfied with their jobs with respect to the effective and efficient use of abilities in organizations (Choudhary et al., 2017). Therefore, higher levels of the employee job match indicate higher levels of work attitude and behavior. Consequently, an employee job match between job requirements and capabilities is essential (Delmas and Pekovic, 2018).

The commitment of an employee to an organization is generally defined as the relative strength of background and involvement of an individual in a particular organization (Meyer et al., 2012). Several studies have revealed that employee organizational commitment is a highly important factor because it can predict turnover (Teo et al., 2020), employee loyalty (Chordiya et al., 2017), and employee performance (Jaiswal et al., 2019). Prior studies have argued that direct involvement from the top management level in diversity-related functions can signal the commitment of an organization to diversity (Gilbert et al., 1999), including diversity as part of the organizational culture (Baytos, 1992). Diversity management can positively affect the affective commitment of employees (Ashikali and Groeneveld, 2015). Therefore, organizations must pay attention to workforce diversity management practices (Madera, 2013).

Structural empowerment refers to the delegation of power and authority by top management to the lower management to strengthen the employer-employee relationship, promote job security, and improve the job performance of an employee (Lee and Kim, 2020). Structural empowerment provides a work environment where all employees are held responsible for their respective job duties, and it gives room for employees to think out of the box and better apply their respective innovative and creative minds to accomplish the given organization goals (Dahinten et al., 2016). Therefore, structural empowerment might serve as a moderating factor in examining the relationship between workforce diversity management and employee job performance.

However, to our knowledge, the mediating effects of both the person-job match and employee commitment and the moderating role of structural empowerment are under discussed, which composes the key research motivation of this study. In addition, 3-fold alternative motivations follow. First, the study investigation, particularly in the Chinese organizational context, is based on the Chinese Belt and Road Initiative (BRI). After the BRI, China had to connect with human diversity (uniquelevel, surface-level, and deep-level diversity) at many fronts to achieve its objective of the community of the shared future, and the main point of contact with BRI countries was through an effective telecommunication sector, which, unfortunately, based on our knowledge, was underexplored (Medeiros, 2009; Kerga and Asefa, 2018; Zongze, 2018).

Second, in the telecommunications sector, customers represent the general population at large (Chun et al., 2019). Individuals from diverse backgrounds (e.g., age, gender, culture, ethnicity) could be potential customers. Therefore, the telecommunication sector requires a diverse workforce to effectively communicate, connect, and understand the variety of customer perspectives (Aceto et al., 2019). The diverse workforce in the telecommunication sector can capture a wider customer base. Indeed, it can exploit new market opportunities and modify the services based on customer needs. We live in a technological era that aims to strengthen person-to-person connectivity. Thus, there is a significant research gap to address individual differences as an asset rather than a liability and its direct positive effects on productivity. As the world has progressed in terms of technology adoption, there are advanced ways to connect, communicate, and create operational work opportunities for growth that require a strong nexus between the telecommunications sector and workforce diversity.

Third, the global coronavirus disease-2019 (COVID-19) pandemic has triggered major shifts in the global economy from a physical work environment and interactions to online virtual workplaces (Kniffin et al., 2021). During the first wave of COVID-19, the telecommunication sector gained importance and further strengthened the standing and effectiveness of the telecommunications sector for economies, irrespective of whether the economy was developing, emerging, or developed (Zhang, 2021). Understanding the role of workforce diversity management would provide the management level of the telecommunications sector with new insight into organization performance management.

Moreover, the key research objective of this study is to explore whether there is a positive relationship between workforce diversity management and employee job performance. Furthermore, to examine how employee commitment and a person job match mediate the relationship between workforce diversity management and employee job performance. In addition, how does structural empowerment moderate 
the strengthening relationship between workforce diversity management and employee job performance?

The above research motivation, objectives, and existing theoretical foundations and literature provide a justification to explore the influence of workforce diversity management on employee job performance (Cho et al., 2017; Shao et al., 2019; Zhuwao et al., 2019) by further considering factors such as the person-job match (Mor Barak, 2015; Byza et al., 2019; Li et al., 2020c), employee commitment (Lau et al., 2017; Ibidunni et al., 2018), and structural empowerment (Lee and Kim, 2020; Maan et al., 2020). The proposed theoretical model and hypotheses are investigated, and the research findings are illustrated as theoretical and managerial implications. Finally, the discussion and conclusion section presents the research results and highlights possible future opportunities.

\section{LITERATURE REVIEW AND HYPOTHESIS DEVELOPMENT}

This study is based on the social exchange theory to emphasize the law of reciprocity that may link employee commitment factors in the relationship between workforce diversity management and employee performance and resource-based theory to support the person-job match in the relationship between workforce diversity management and employee performance. Based on the social exchange theory, employees that are provided either monetary or non-monetary rewards, perks, and fringe benefits by their organizations are generally more committed to their respective jobs and spend extra effort to perform well and not leave their jobs (Yu et al., 2018; Zagenczyk et al., 2020). It further confirms the law of reciprocity (Gouldner, 1960). This study has used the contemporary aspect of resourcebased theory to explain employee-based resources can provide a competitive advantage to an organization when the person-job match is relevant to organizational competencies that provide enabling environment for both employees and organizations for effective allocation of available resources (Wernerfelt, 1984; Collins, 2021). Moreover, Kanter's structural empowerment theory is used to observe the strengthening role of structural empowerment in the relationship between workforce diversity management and employee performance (Kanter, 1993). Kanter's theory of structural empowerment put forth arguments on organizational behavior and empowerment. Based on this theory, empowerment is encouraged in work environments that offer employees access to resources, information, a platform to learn and innovate, and opportunity for optimal resource utilization (Zhang et al., 2018; Arslan Yürümezoglu and Kocaman, 2019).

\section{Workforce Diversity Management and Employee Job Performance}

Workforce diversity management refers to taking an action to accomplish a specific task that positively or negatively influences the environment (Shao et al., 2019). Workforce diversity management results in low turnover expectations, high hierarchical responsibility, and high firm performance.
Work-related variety has been associated with providing an environment for workforce diversity management that fortifies the performance of both individuals and organizations ( $\mathrm{Li}$ et al., 2017, 2020c). According to Park and Liang (2020), workforce diversity management and performance practices independently affect authoritative execution. Moreover, they contend that successful workforce diversity management will prompt the board for expansion in certain legitimacy-based work to bring about improvement in hierarchical performance. It can be inferred that workforce diversity management provides variety for executives by identifying individuals based on their aptitude and specialization, which eventually leads to higher employee performance. Along these lines, workforce diversity management aims to maintain an ideal workplace environment by giving the representatives merit-based occupation for the powerful use of the abilities of representatives to perform better employment (Zhuwao et al., 2019). Lee and Kim (2020) examined and uncovered an alternate viewpoint concerning workforce diversity and employee performance by incorporating segment credits (age, sexual orientation, nationality, and related demographics) and examining related characteristics (work, residency, premium, inclinations, and related information).

Accordingly, it is coherent to expect that workforce diversity management considers oversees representatives with particular information, abilities, interests, and inclinations. It will also guarantee an environment in which segregation will not occur based on age, sexual orientation, identity, capacities, abilities, or other identifying information. Past research shows that labor force variety establishes a positive workplace environment and improves employee performance (Cho et al., 2017). A positive work environment creates good representatives and associations, improving satisfaction and the hierarchical execution of workers. Past investigations related to the variety show that workforce diversity management improves the job performance of representatives and employees (Rizwan et al., 2016; Moon and Christensen, 2020). Therefore, we propose the following hypothesis.

H1: Workforce diversity management is positively related to employee job performance.

\section{Workforce Diversity Management, Person-Job Match, and Employee Job Performance}

Workforce diversity management is viewed as perceiving, understanding, enduring, regarding, and praising dissimilarities among people concerning an entire scope of dissimilarities related to age, class, nationality, sex, physical and scholarly limit, race, money-related status, sexual orientation, or religion (Lee and Sabharwal, 2016). Moreover, Yadav and Katiyar (2017) asserted that qualities, authoritative jobs, and proficient and social styles might affect the job match of a person. Gomez and Bernet (2019) clarified that workforce diversity improves employee performance. It generates higher incomes and numerous other monetary rewards, for example, advancement, promotions, increased efficiency, and improved accuracy. Individual employment coordinates are related to 
the arrangement between an individual and the working environment (Huang et al., 2019). Prior studies reported a positive and significant relationship between a personjob fit, workplace diversity, and employee job performance (Li et al., 2020c).

Moreover, previous literature shows that the job match of a person is typically considered a positive component in the workplace (Sengers et al., 2020). Previous research has neglected to consider the importance of a person-job fit and employee job performance in the workplace as predictors (Mor Barak, 2015; Byza et al., 2019). Furthermore, based on this premise, the higher the match between a representative and his or her work regarding position-related information and abilities, the higher the subsequent degree of execution of workers should be (Choi and Rainey, 2010). Additionally, representatives whose range of abilities firmly coordinates their expected set of responsibilities are considered to have adequate perception and capacities to fulfill their employment prerequisites and more grounded fitness for contending with the advancement cycle. According to Sylva et al. (2019), representatives who accept that they have a great job fit in the work environment will show a compact ability to work and accomplish more development practices, which will ultimately fulfill personnel work execution.

In addition, scholars have found that job match positivity is related to employee performance and plays a mediating role in the relationship between workforce diversity and job performance (Choi and Rainey, 2010; Li et al., 2020c). Moreover, many individuals do not obtain their desired jobs based on their academic qualifications or technical skills. Their job performance does not correspond to desired levels of an organization (Huang et al., 2019). For instance, holding a management degree opens a broader spectrum of opportunities. Nevertheless, during the hiring process, the specialized field of interest is generally asked to best discern the skills of an individual. Furthermore, there are many specialties within management, such as innovation and management, economic systems and management, environmental management, and financial management. Therefore, if an individual with entrepreneurial management expertise is assigned to the financial management department, he or she might not perform effectively compared with financial management experts (Bhat and Rainayee, 2019). Therefore, it is important to understand both for the employee and the employer the linkage between workforce diversity and the job match of a person, as it ultimately affects organizational performance.

Various studies have explained the influence of the job match of a person, for example, attributes of the work, work setting, and rewards (Huang et al., 2019). An employee may go the extra mile to achieve work objectives, despite mental and physical exertion and spending extra time. Once the employee reaches this point, the worker will boost the performance of an organization. Furthermore, this scenario will result in higher occupation fulfillment, higher employment execution, and higher hierarchical exhibitions. Person-job matches consider segregation and disparity, which could influence the performances of representatives (Wu et al., 2020). Investigations have had the option to state that the employment coordinate of an individual is a solid indicator of low occupation stress, responsibility, inspiration, work fulfillment, and employment execution (Lee and Kim, 2020; Li et al., 2020a,b,c). A person-job match is essential for understanding the aptitudes, information, and capacities of individuals. A better match encourages a more prominent work disposition and behavior. It also increases employment fulfillment and employee job performance. Based on the above discussion, we propose the following hypotheses:

H2a: Workforce diversity management is positively related to a person-job match.

H2b: The person-job match is positively related to employee job performance.

\section{Workforce Diversity Management, Employee Commitment, and Employee Job Performance}

In prior research, understanding the concept of employee commitment from the management science and social science research perspective has spurred various discussions on heterogeneity in execution results (Ibidunni et al., 2018). As indicated by a developed exploration, it has been shown that, in employee commitment, individuals from one of the more prominent minority groups are apt to leave the association and experience the hostile effects of higher rates of absenteeism (Brimhall, 2019). Additionally, unique diversity-related activities, the dedicated diversity of the board staff and work environment projects and advantages, for example, adaptable work game plans, homegrown accomplice benefits, corporate-supported worker proclivity gatherings, and different projects, are planned and elevated by associations to help attract and retain a diverse labor force (Cho et al., 2017).

However, there are differences in workplace diversity and connection among representatives of employees and how representatives feel about their work and boss, work/profession fulfillment, work contribution, hierarchical distinguishing proof, deals execution, and authoritative adequacy (Zhuwao et al., 2019). A strong connection between employee commitment and the workplace has been found by Jyoti et al. (2021), Hasan et al. (2021), Therasa and Vijayabanu (2016), and Laschinger et al. (2006), based on employee commitment and person-job match hypotheses. The level of solace and comfort of employees at an organization is higher when the variety/diversity of employees is high instead of low because of the impression of care among representatives (Meyer et al., 2012). Thus, these insights add to the attractiveness of an association, as workers decided to stay faithful to the association with diminished turnover intentions (Goswami and Goswami, 2018). This viewpoint is upheld by research that argues that diversity increases fearlessness, which improves employee performance caused by the sensations of disappointment and recognizable proof with work and association of one (Cho et al., 2017). Therefore, it can be inferred that strengthening workforce diversity management leads to higher employee commitment, which further improves employee and organizational performance. 
Similarly, employee commitment is related to employee job performance or interest in the associations (Lau et al., 2017). Employee commitment is critical because it determines whether workers are likely to find employment elsewhere or improve their performance. Various studies have emphasized employee commitment. Ramdhani et al. (2017) discussed attitudinal employee commitment and employee behavior in an organization. According to this methodology, employee commitment has three multidimensional measures: emotional commitment, duration commitment, and regulating commitment (Meyer et al., 2004). Full employee commitment, which identifies enthusiastic connections, is typically connected to a great workplace and associations with different representatives (Cho et al., 2017). Standardizing responsibility is identified with commitment: representatives may feel they owe an association for being given work when they need it most. Finally, continuation responsibility refers to such terms of work as employment contracts, the decision to leave the present place of employment because of expenses or fatigue (Hofmann and Stokburger-Sauer, 2017).

Employee performance and employee commitment inferable from hierarchical climate have become a significant migraine for numerous heads of associations and human resources directors specifically (Garg, 2017). This issue is generally inferred from the absence of strength and professional stability among workers, who are possibly the main assets of an association. Numerous links have started to cultivate the obligation of laborers to their work/occupation/profession, to an association, its qualities and desire, and a solid employment ethic (Cesário and Chambel, 2017).

Moreover, the workforce focuses on its association and is glad to be a part of it, trusts in it, has a positive outlook on the association and serves as a large motivator for it, and plans to do what is useful for the association (Andrew, 2017). In this respect, we could list any connection between employee commitment and employee performance. However, shockingly, past research proposed that employee commitment is, to a great extent, disconnected from work performance (Ozcelik and Barsade, 2018). Employee commitment alludes to the mental connection of laborers to their working environments (Al Zefeiti and Mohamad, 2017). Thus, based on the above discussion, we predicted the following hypotheses:

H3a: Workforce diversity management is positively related to employee commitment.

H3b: Employee commitment is positively related to employee job performance.

\section{Mediating Effect of a Job Match and Employee Commitment of a Person}

To the extent that improved labor force diversity influences the person-job match and show an individual that his or her skill is appropriately coordinated with work interest (H2a), an increase in a person job match contributes to an increase in employee job performance $(\mathrm{H} 2 \mathrm{~b})$; thus, there is an indirect connection between a person-job match, workforce diversity, and employee job performance. More specifically, workforce diversity contributes to a job match of a person through its impact on employee job performance.

In contrast, employee commitment is distinctly identified with such insightful results specific to employee performance (Chordiya et al., 2017). More grounded responsibility could reduce turnover and non-attendance, consequently expanding the profitability of an organization (Cesário and Chambel, 2017). In many cases, the connection between employee commitment and employee job performance is more unstable (Delmas and Pekovic, 2018). For example, a meta-investigation indicated that certainty concerning the mean connection between the number of employee commitments and performance is zero. Hence, it was concluded that commitment generally has a minimal direct effect on workforce diversity and performance in many instances (Goswami and Goswami, 2018). Employee commitment is a significant determinant of improved work and integral to comprehension and overseeing authoritative behavior; however, it would be insightful to know whether it is correct that they are, to a great extent, irrelevant to one another (Klein et al., 2014). Therefore, we hypothesize the following:

H2c: The person-job match positively mediates the relationship between workforce diversity management and employee job performance.

H3c: Employee commitment positively mediates the relationship between workforce diversity management and employee job performance.

\section{Structural Empowerment and Employee Job Performance}

Structural empowerment indicates any organization primarily delegating authority and obligation to workers in lower places of the authoritative chain of command (Lee and Kim, 2020). Structural empowerment is a post administrative hierarchical activity that creates a work environment where everybody feels liable for the accomplishments of an organization and accordingly offers to arrange their activities successfully (Yadav and Katiyar, 2017). Structural empowerment has been affirmed as an approach that urges representative participation and improves the work environment (Dahinten et al., 2016). It also promotes the self-rule, strength effect, and occupational satisfaction of workers through upgrading with a higher delegation of power (Asif et al., 2019). By planning work in a manner that permits and propels representatives to partake in significant dynamic cycles, firms can encourage correspondences and collaborations (i.e., social coordination) even among individuals with diverse backgrounds.

Hence, we propose emphasizing a striking work setting that advances social coordination among the diverse labor force. In any case, primary strengthening features the upsides of variety and incites representatives to acquire new abilities and information from individuals with diverse backgrounds. Conspicuously, labor force diversity is insightful regarding a wide arrangement of information, skills, and experiences. When associations underscore the significance of these advantages, workforce diversity delivers a much more prominent effect (Choi et al., 2016). Thus, we propose the following: 
H4: Structural empowerment is positively related to employee job performance.

\section{Moderating Role of Structural Empowerment}

Structural empowerment refers to organization delegation of power, authority, and responsibility from senior-level management to lower levels of management (Mintzberg, 1979; Leach et al., 2003). It is a concept where every worker feels responsible for either success or failure of the organization; therefore, it encourages an employee's self-accountability for effective work management (Heckscher, 1994). The existing literature confirms that structural empowerment encourages employees to actively participate in the respective organization processes and improves the overall work performance by designing the work in a manner that promotes employees to have a deeper understanding and effective communication among diverse members (Mills and Ungson, 2003; Spreitzer and Doneson, 2005; Mathieu et al., 2006; Spreitzer, 2008). Structural empowerment signifies the benefits of workforce diversity, and, parallelly, it motivates employees to learn new skills and gain knowledge from diverse affiliates. Moreover, workforce diversity management has a broad set of benefits: multiple aspects of knowledge, expertise, and intellectual wisdom. Therefore, when an organization promotes structural empowerment, it translates into a strengthening impact on employee performance. Spreitzer and Doneson (2005) explain that organizations practicing delegation of power among employees experience well-motivated, innovative, and effective employee performance. Thus, structural empowerment encourages better participation, more involvement in decision-making, and establishes effective communication with individuals from diverse backgrounds. Putri and Djastuti (2019) argued that diversity prompts successful task application and measures; therefore, when undertakings require the pooling and preparation of various viewpoints, workers from diverse backgrounds are given the inspiration and opportunity to impart their respective unique experiences. Thus, when organizations delegate authority and responsibility, the representatives who take responsibility for work are inspired to initiate changes and developments (Amor et al., 2020).

Therefore, the requirement for advancement incites workers to incorporate an expansive arrangement of information and viewpoints by collaborating with and learning from individuals from diverse backgrounds. First, authoritative structures that energize strengthening can stifle classification and misconception among individuals from various backgrounds (Maan et al., 2020). Workplaces should open doors for representatives to partake in undertaking measures and collaborate with individuals from various social gatherings. These open doors initiate open representative associations and helpful practices, which can advance the development of shared objectives, shared information, and common regard (Lee and Kim, 2020). Hence, there is an explanation of the notion that structural empowerment strengthens the positive effect on the relationship between workforce diversity management and employee job performance. It is well-explained above and supported by both empirical and theoretical evidence that workforce diversity management plays a key role in improving employee job performance. In a similar vein, if the diverse workforce delegates more tasks at any level of an organization, it will provide them with additional boosts and confidence to tackle the tasks. In some situations, it also enhances the mental well-being of employees, as it signals the sentiment of appreciation and acknowledgment (Akinola et al., 2018; Amor et al., 2020; Snowdon et al., 2020). Thus, a higher level of structural empowerment can serve as a moderating factor in explaining the relationship between workforce diversity management and employee job performance. Therefore, this study put forth structural empowerment as a moderator variable that is expected to strengthen the relationship between workforce diversity management and employee job performance. Based on this notion, we propose the following:

H4a: Structural empowerment positively moderates the relationship between workforce diversity management and employee job performance.

\section{MATERIALS AND METHODS}

Data were collected from the telecommunications sector located in Jiangsu Province, China. The current study was conducted using a cross-sectional method. This study took telecommunications sector employees into account to gather data because research on this sector has been neglected in the past (Kundu and Mor, 2017; Lee and Kim, 2020; Moon and Christensen, 2020). However, with the BRI by China, there is a higher emphasis on better connectivity among cross-border countries, which requires an efficient telecommunications sector to achieve the key objectives (Edquist et al., 2018; Paglierani et al., 2020).

\section{Conceptual Model}

In this study, Chinese participants were taken as the research subject to investigate the relationship among the variables, including workforce diversity management (WDM), person-job match (PJM), employee commitment (EC), structural empowerment (SE), and employee job performance (EJP), and then examine the mediating role of the mediating effect of a person-job match and employee commitment and the moderating role of structural empowerment. According to the hypotheses proposed above, we created the conceptual model shown in Figure 1.

\section{Pilot Survey and Instrumental Design}

A preliminary questionnaire was formulated based on the existing established and validated scale. Before conducting the final survey, we had adjusted and integrated these developed scales as the final questionnaire of the study. Hence, before the circulation of the questionnaires, we had randomly selected 45 volunteers from the telecommunications sector of Jiangsu Province to complete the pretest questionnaire and further determined its presentation and content validity. Based on pilot survey feedback and observing the language expression habits 


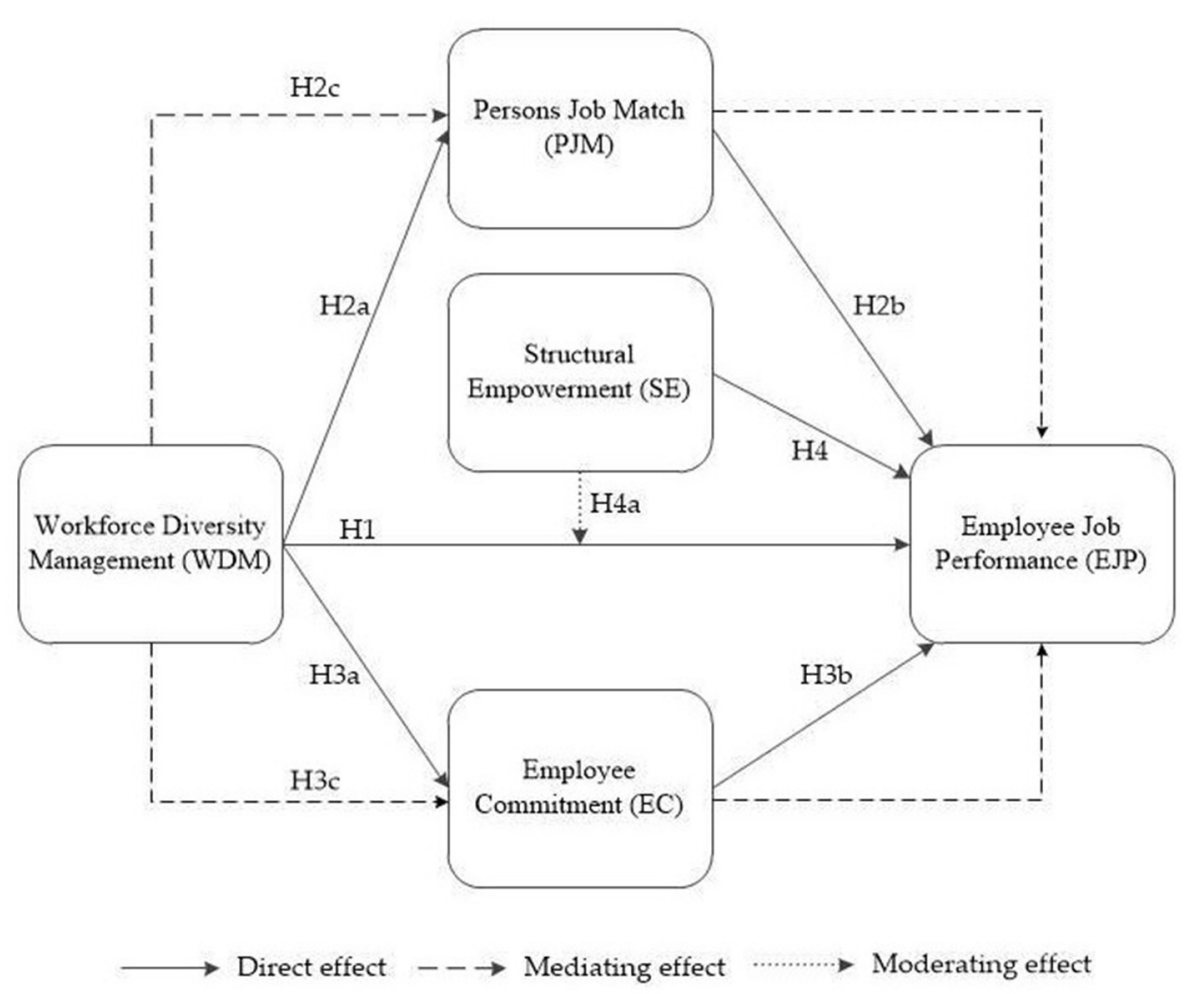

FIGURE 1 | Conceptual model. WDM, workforce diversity management; PJM, person job match; EC, employee commitment; SE, structural empowerment; EJP, employee job performance.

in the Chinese context, we designed the final version of the questionnaire to improve the relevance and readability of the survey instrument, which included 26 constructs.

\section{Sampling Technique and Demographic Information}

The population of this study comprised lower-, middle-, and senior-level workers from the telecommunications sector of Jiangsu Province, China. The province selection was based on the fact that Jiangsu Province is considered one of the richest provinces of China (Wei et al., 2020). Specifically, data for this study were collected from three telecommunications companies located in Jiangsu Province, China Telecom, China Mobile, and China Unicom from September 2019 to June 2020. Prior to the circulation of the questionnaires, researchers and enumerators had visited all the respondents to clarify the purpose and procedures for administering the survey. Data collection started before the outbreak of COVID-19. A total of 600 voluntary participants were recruited. The team of the trained researcher informed the participants that their participation is voluntary and anonymous. All the data were kept confidential and abided by scholarly ethical principles. The respondents were instructed to seal completed questionnaires in envelopes and return them to the researchers if the participants completed the survey physically; as China was affected by the COVID-19 outbreak, from January 2020 to June 2020, the participants submitted responses electronically through an online questionnaire survey.

There were 600 questionnaires, of which 492 questionnaires were retained after discarding 92 incomplete or invalid responses. A total of 400 questionnaires were kept for data analysis, yielding a $66.67 \%$ response rate. Based on the demographic information, we computed the following statistics. Among the valid questionnaires, 204 (51\%) were completed by males and $196(49 \%)$ by females. The age range was from 18 to 35 years and above, and the mean and standard deviation of age values were $1.82-0.890$. The highest response rate of $50 \%$ of respondents falls in the age bracket of 18-25 years, followed by the 2530 years age bracket that provided 35\% responses, and the remaining 15\% were above 30 years and working in executive positions. Furthermore, the highest education response was an undergraduate degree, which accounted for $57.3 \%$. In terms of organization distribution of respondents, 188 (47\%) were from China Unicom, 82 (20.5\%) were from China Mobile, and the rest were from China Telecom.

\section{Measures}

We adapted scales, such as workforce diversity management, person-job match, employee commitment, structural empowerment, and employee job performance. These measurement constructs were previously used and verified by many scholars (Huang et al., 2019; Lee and Kim, 2020). All the 
questionnaire items were measured with a five-point Likert scale ranging from 1, strongly disagree, to 5, strongly agree. Employee job performance was measured using a four-item scale adapted from Yousef (2000). The following is a sample item: "How would you rate the overall quality of work done by your workgroup?" Cronbach's alpha for employee job performance was 0.933, which meets the threshold value of the 0.70 criteria used by prior researchers (Nunally and Bernstein, 1978; Li et al., 2020b). Workforce diversity management is defined as the dissemination of individual characteristics among interrelated associates of an organization, which has become a widely accepted phenomenon (Cho et al., 2017; Lee and Kim, 2020). Existing research poses the components of unique, surface-level, and deep-level diversity to account for holistic aspects of workforce diversity management. Furthermore, workforce diversity management was measured using three scale-adapted items (Choi and Rainey, 2010). The following is a sample item: "Policies and programs promote diversity in the workplace." Cronbach's alpha for workforce diversity management was 0.909 . Structural empowerment was assessed using a seven-item scale adapted from Lee and Kim (2020). The following is a sample item: "I am satisfied with my task allocation." Cronbach's alpha for structural empowerment was 0.921 . The person-job match was evaluated using a threeitem scale developed by Mulki et al. (2006). The following is a sample item: "There is a good fit between my job and me." Cronbach's alpha for the person-job match was 0.883 . Finally, employee commitment was measured using four items from the study of Klein et al. (2014). These items are widely used to assess employee commitment in the context of workforce diversity. The following is a sample item: "How committed are you to your target?" Cronbach's alpha for employee commitment was 0.898 .

\section{RESULTS}

\section{Data Analysis Technique}

To analyze the proposed hypotheses, structural equation modeling (SEM) was used, which was generated by AMOS version 24.0. SEM also incorporates measurement error and can reveal best-suited predictions of interaction influences, such as mediation (Hair et al., 2016; Li et al., 2020b).

\section{Measurement of Model}

Confirmatory factor analysis was performed to assess the model fitness, and the results are highlighted in Figure 2. The initial model for this study was modified by considering the modification indices because of the incomplete model fit. To predict the goodness-of-fit index of the model, the results were expressed as follows: Chi-squares $=419.827, \mathrm{DF}=179$, $\mathrm{CMIN} / \mathrm{DF}=2.345$ (should be $<5$ ), $\mathrm{CFI}=0.952, \mathrm{NFI}=0.919$, $\mathrm{GFI}=0.901, \mathrm{AGFI}=0.872, \mathrm{TLI}=0.943, \mathrm{IFI}=0.952, \mathrm{RFI}=$ $0.905, \mathrm{SRMR}=0.041, \mathrm{RMSEA}=0.059$, and PCLOSE $=0.113$. The measurement model meets the threshold values suggested by $\mathrm{Hu}$ and Bentler (1999), which shows that the model fit is good.

\section{Reliability and Validity Test}

Reliability and validity analyses were assessed using master validity analysis, and the values are shown in Table 1.
Through Cronbach's alpha and composite reliability, the overall reliability was assessed. Cronbach's alpha refers to internal item consistency and is considered a popular reliability measurement tool. Moreover, composite reliability is deliberated to superior alternative reliability compared to the alpha coefficient. Convergent and discriminant validity assessed overall model validity. As suggested by Bagozzi and Yi (1988), the value of the average variance extracted (AVE) should be $>0.50$. Additionally, we followed the criteria of Fornell and Larcker (1981) to determine discriminant validity. This approach is generally used to assess discriminant validity. It explains that the square root and AVE of each construct should be greater than the correlation values with any other construct.

\section{Common Method Bias}

This study performed the one-factor analysis of Harman (1967) to test for common method bias. This methodology tests whether variations in the data are accounted for by only one variable. If a single variable accounts for more than $50 \%$ of the data variance, then there is the challenge of common method bias (Podsakoff et al., 2003). The rotated factor matrix shows four extracted items (following the constructs), with the first factor having $37.57 \%$ of the variance explained. Thus, there was no potential problem of common method bias.

\section{Structural Model}

Before testing the results of the hypotheses, we had examined the adaptability of the structural model using AMOS version 24.0, and Figure 3 shows the results. For the prediction of the goodness-of-fit index of the model, the results were expressed as follows: Chi-squares $=52.724, \mathrm{DF}=32, \mathrm{CMIN} / \mathrm{DF}=1.648$, $\mathrm{CFI}=0.992, \mathrm{NFI}=0.980, \mathrm{GFI}=0.974, \mathrm{AGFI}=0.956, \mathrm{TLI}=$ 0.989 , IFI $=0.992, \mathrm{RFI}=0.973, \mathrm{SMRM}=0.031$, and RMSEA $=0.040$. To assess the variance of the measures, the structural model explained $9 \%$ of the variance in the person-job match, $4 \%$ of the variance explained employee commitment, and $28 \%$ of the variance in employee job performance. As suggested by Chin (1998), desired $R^{2}$ values must be $>0.1$ or zero. Thus, these results are unsurprising, as most job matches of workers and employee job performance models in previous studies have only explained between 10 and $30 \%$ of the variance (Choi and Rainey, 2010; Lee and Kim, 2020; Li et al., 2020b).

\section{Hypothesis Testing}

The results of the regression analysis are detailed in Table 2. To test the hypotheses, we predicted that workforce diversity management positively influences employee job performance and found a positive and significant impact of workforce diversity management on employee job performance $(\beta=0.247, p=$ $0.003)$; thus, $\mathrm{H} 1$ was supported. We also predicted that $\mathrm{H} 2 \mathrm{a}$ workforce diversity management positively influences a personjob match, and the results reveal that workforce diversity management had a significant impact on the person-job match ( $\beta=0.223, p=0.001)$; hence, $\mathrm{H} 2 \mathrm{a}$ was supported.

Moreover, we predicted that a person-job match was positively related to employee job performance, and the findings indicate that the person-job match had a significant 


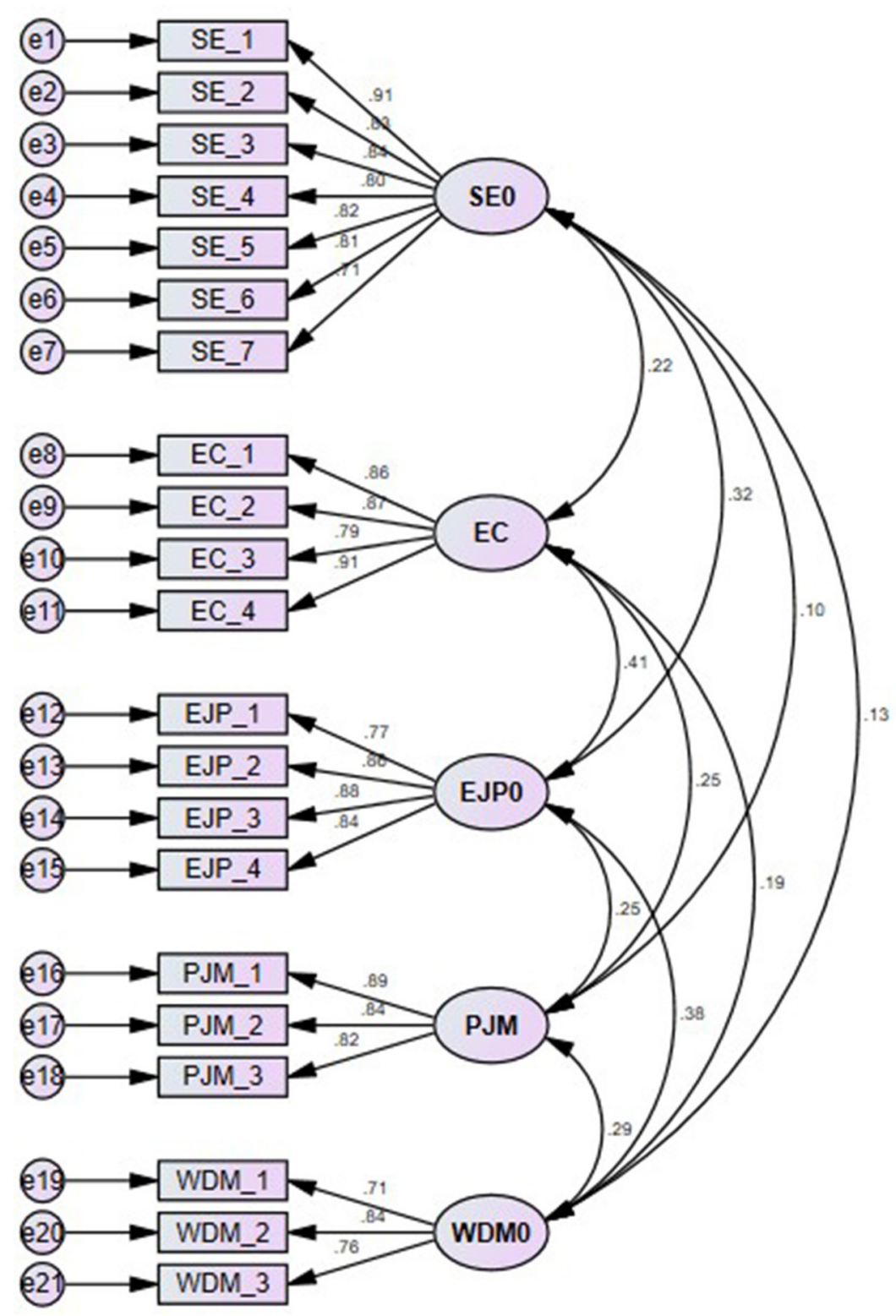

FIGURE 2 | Conformity factor analysis. WDM, workforce diversity management; PJM, person job match; EC, employee commitment; SE, structural empowerment; EJP, employee job performance.

TABLE 1 | Reliability and validity analysis.

\begin{tabular}{|c|c|c|c|c|c|c|c|c|c|}
\hline & CR & AVE & MSV & $\operatorname{MaxR}(\mathrm{H})$ & SE & EC & EJP & PJM & WDM \\
\hline EC & 0.917 & 0.735 & 0.170 & 0.925 & $0.220^{\star \star \star}$ & 0.857 & & & \\
\hline PJM & 0.886 & 0.723 & 0.083 & 0.891 & $0.099^{*}$ & $0.252^{\star \star \star}$ & $0.246^{\star \star \star}$ & 0.850 & \\
\hline WDM & 0.814 & 0.595 & 0.145 & 0.826 & $0.129^{\star}$ & $0.190^{\star \star}$ & $0.381^{\star \star \star}$ & $0.288^{\star \star \star}$ & 0.771 \\
\hline
\end{tabular}

Values in diagonals are square root of AVE; values under diagonals are correlations. $C R$, composite reliability; AVE, average variance extracted; MSV, maximum shared variance; SE, structural empowerment; EJP, employee job performance; WDM, workforce diversity management; $P J M$, person job match; $E C$, employee commitment. ${ }^{\star \star \star} p<0.001$, ${ }^{\star *} p<0.005$, and ${ }^{*} p<0.01$. 


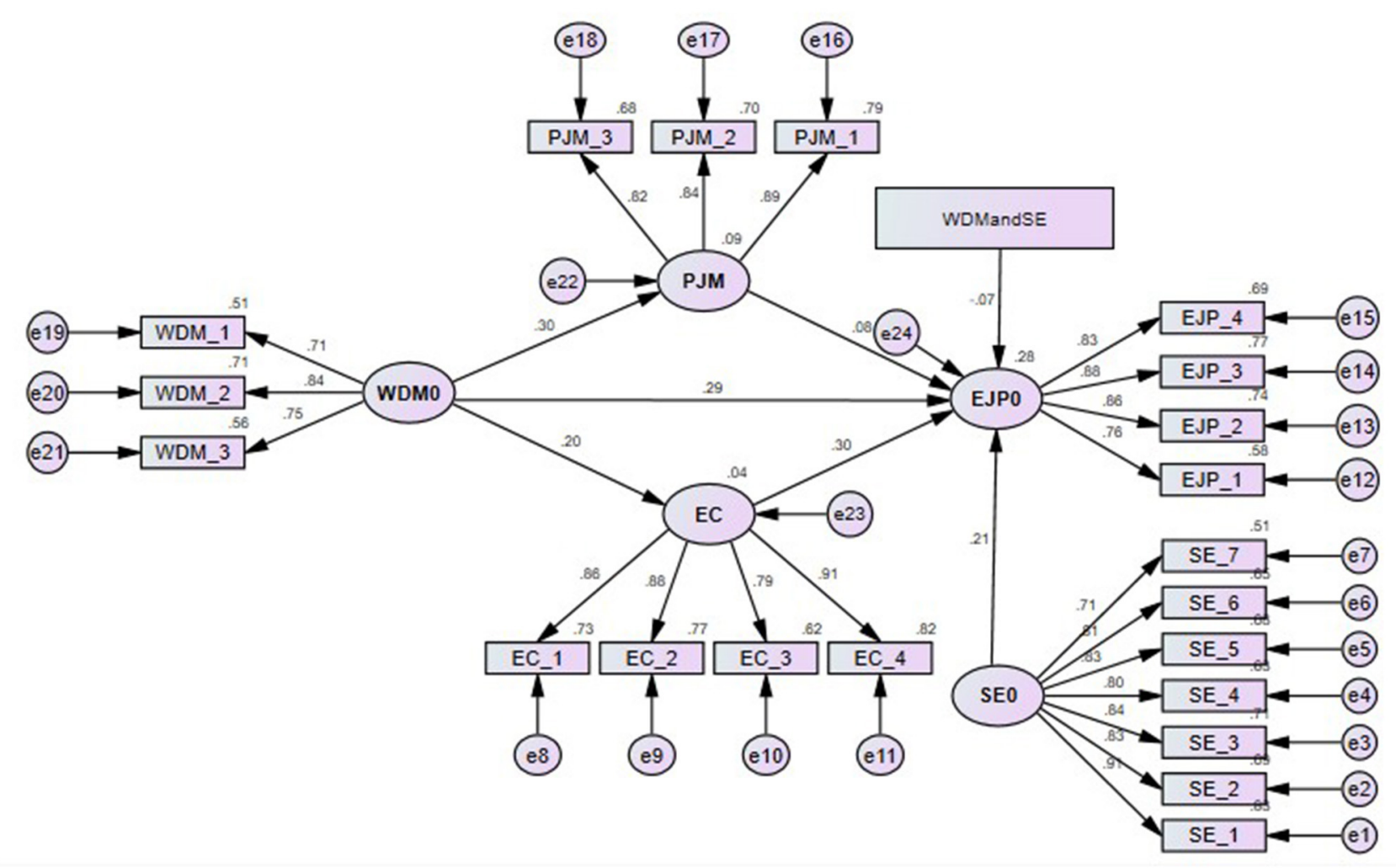

FIGURE 3 | Structural model. WDM, workforce diversity management; PJM, person job match; EC, employee commitment; SE, structural empowerment; EJP, employee job performance.

TABLE 2 | Structural model estimates.

\begin{tabular}{|c|c|c|c|c|c|}
\hline Hypothesis & Relationships & Standardized estimates & S.E. & C.R. & $p$-value \\
\hline $\mathrm{H} 1$ & $\mathrm{WDM} \rightarrow \mathrm{EJP}$ & $0.247^{\star \star}$ & 0.059 & 4.738 & 0.003 \\
\hline $\mathrm{H} 2 \mathrm{a}$ & WDM $\rightarrow$ PJM & $0.223^{\star \star}$ & 0.061 & 4.079 & 0.001 \\
\hline H3а & $\mathrm{WDM} \rightarrow \mathrm{EC}$ & $0.298^{\star \star}$ & 0.091 & 3.287 & 0.001 \\
\hline $\mathrm{H} 3 \mathrm{~b}$ & $\mathrm{EC} \rightarrow \mathrm{EJP}$ & $0.243^{\star \star}$ & 0.045 & 5.441 & 0.001 \\
\hline
\end{tabular}

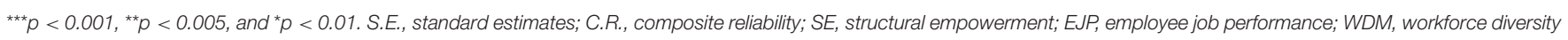
management; PJM, person job match; EC, employee commitment.

effect on employee job performance $(\beta=0.159, p=$ 0.002 ), thereby supporting $\mathrm{H} 2 \mathrm{~b}$. Additionally, we predicted that workforce diversity management was positively related to employee commitment, and the findings indicate that workforce diversity management had a significant effect on an employee commitment ( $\beta=0.298, p=0.001$ ), so H3a was supported. Furthermore, we have assumed that employee commitment positively influences employee job performance. The results illustrate that employee commitment positively and significantly impacted employee job performance $(\beta=0.243, p=0.001)$, thus supporting $\mathrm{H} 3 \mathrm{~b}$.

Additionally, we assumed that structural empowerment positively influenced employee job performance, and the results illustrate that structural empowerment had a positive and significant impact on employee job performance $(\beta=0.302, p$ $=0.001)$. Thus, $\mathrm{H} 4$ was also supported.

\section{Mediation Analysis}

For the mediation analysis, we hypothesized that person-job match and employee commitment mediate the relationship between workforce diversity management and employee job performance. Mediation analysis was performed using a $95 \%$ confidence interval with 5,000 bootstrapping methods to identify the lower and upper bounds proposed by Preacher and Hayes (2008). The results are provided in Table 3. We estimated the standardized direct effect, standardized indirect 
TABLE 3 | Mediation analysis (Bootstrapping).

\begin{tabular}{lcccc}
\hline Relationships & $\begin{array}{c}\text { Standardized } \\
\text { indirect effects }\end{array}$ & $\begin{array}{c}\text { Bootstrapping } \\
\text { percentile method } \\
\text { lower and upper }\end{array}$ & $\begin{array}{c}\text { Standardized } \\
\text { direct effects }\end{array}$ & $\begin{array}{c}\text { Standardized } \\
\text { total effects }\end{array}$ \\
\hline WDM $\rightarrow$ PJM $\rightarrow$ EJP & $0.035^{\star \star}$ & $0.006-0.077$ & $0.247^{\star \star}$ & $0.283^{\star \star}$ \\
$W D M \rightarrow E C \rightarrow E J P$ & $0.045^{\star \star}$ & $0.0010-0.098$ & $0.243^{\star \star}$ & $0.288^{\star \star}$ \\
\hline
\end{tabular}

${ }^{\star \star *} p<0.001,{ }^{* \star} p<0.005$, and ${ }^{*} p<0.01$. SE, structural empowerment; EJP, employee job performance; WDM, workforce diversity management; PJM, person job match; EC, employee commitment.

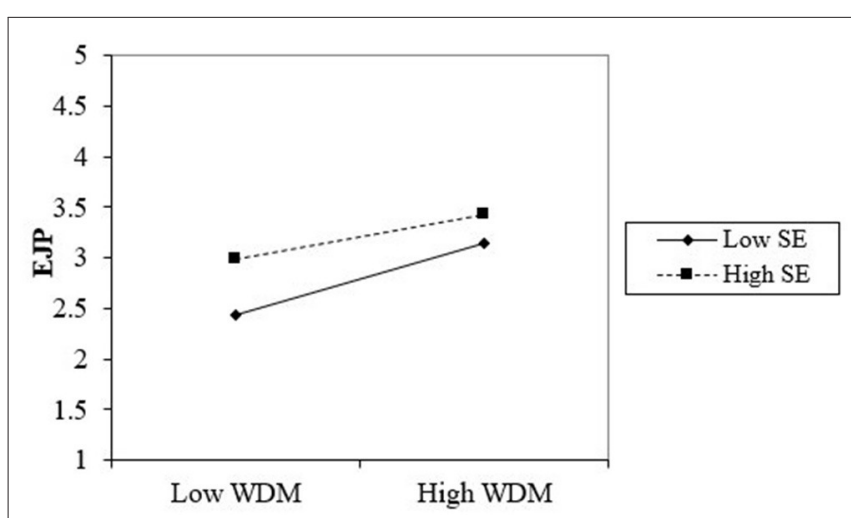

FIGURE 4 | Interaction graph SE*WDM and EJP. WDM, workforce diversity management; SE, structural empowerment; EJP, employee job performance.

effect, and standardized total effect in the bootstrapping method. A significant indirect effect specifies the presence of mediation if $p<0.05$, and if the direct effect is also significant $(p<0.05)$, it shows partial mediation, whereas if the direct effect is non-significant $(p>0.05)$, it indicates full mediation. The findings show that personjob match has an indirectly standardized path coefficient $(\beta$ $=0.035, p<0.01)$ in mediating the relationship between workforce diversity management and employee job performance. Moreover, the findings show that employee commitment has an indirectly standardized path coefficient $(\beta=0.045, p<$ 0.01 ) in mediating the relationship between workforce diversity management and employee job performance. Thus, we can confirm that the person-job match and employee commitment partially mediate the relationship between workforce diversity and employee job performance. Thus, $\mathrm{H} 2 \mathrm{c}$ and $\mathrm{H} 3 \mathrm{c}$ were also supported.

\section{Moderating Effect}

We have predicted that structural empowerment moderates the relationship between workforce diversity management and employee job performance. The results in Figure 4 and Table 4 indicate that structural empowerment had a moderating effect on the relationship between workforce diversity management and employee job performance ( $\beta=-.130, p=0.007)$. Hence, H4a was supported.

\section{DISCUSSION}

The present study examined the procedure through which workforce diversity management affects employee job performance. The outcome demonstrates that workforce diversity promotes better work performance, which is in accordance with change theory, and explains that workforce diversity management of employees prompts higher employee performance, which is consistent with earlier examinations (Choi and Rainey, 2010; Li et al., 2020c). Numerous comparative investigations shed light on the connection between workforce diversity and different person-job matches, for example, worker commitment, representative citizenship behavior, representative turnover aim, work-life fulfillment, worker responsibility, work results, work fulfillment, and efficiency. A portion of the examinations indicates that diversity has positive and negative effects on different variables, such as workforce diversity and employee performance (Joshi and Jackson, 2003). In this investigation, the empirical evidence obtained from the Chinese telecommunication sector supports a constructive recommendation of a diverse workforce and its positive influence on employee performance. Numerous past investigations established a critical connection between workforce diversity and employee performance; however, this examination has been among infrequent investigations to review the positive effect of employee commitment and the personjob match in the relationship between workforce diversity management and employee performance.

The mediating roles of the person-job match and employee commitment on the relationship between workforce diversity management and employee job performance have gained less attention, especially in the Chinese context. In the contemporary context, maintaining the association of an employee with peer employees is a major organizational challenge. Due to diminishing occupation certainty, employees must switch to different positions to expand, grow, and diversify at multiple fronts. Therefore, creating an ideal work environment is not the only challenge faced at an organizational level (Madera, 2013). Past investigations have discovered a positive effect of occupation of an individual on employment fulfillment, responsibility, and execution and a negative effect on representative turnover goals (Li et al., 2020c). Bassett-Jones (2005) characterized workforce diversity on the broader spectrum by examining segment contrasts through inclinations, capacities, and interests. A comparative study recommends that a certain variety of 
TABLE 4 | Moderating effects.

\begin{tabular}{|c|c|c|c|c|c|}
\hline Hypothesis & Relationships & Standardized estimates & S.E. & C.R. & $p$-value \\
\hline $\mathrm{H} 4 \mathrm{a}$ & $\mathrm{SE}{ }^{\star} \mathrm{WDM} \rightarrow \mathrm{EJP}$ & $-0.130^{\star \star}$ & 0.41 & -2.709 & 0.007 \\
\hline
\end{tabular}

atmospheres can result in better employee commitment and employee job performance (Huang et al., 2019).

This empirical analysis shows a significant and positive mediating role of the person-job match and employee commitment on the relationship between workforce diversity management and employee job performance. It further verifies that the person-job match and employee commitment both relate to the inclinations, aptitudes, capacity, and interest of an employee; therefore, it acts as a strengthening factor to determine the relationship between workforce diversity management and employee job performance.

Currently, workforce diversity management entails managing position issues for incorporating and improving influential performance. Thus, the connection between workforce diversity and employee commitment appears legitimate, greatly affecting different hierarchical results. The outcomes also demonstrate the effect of workforce diversity on employee job performance through strong employee commitment, conflicting with valuable suggestions. A recent investigation has shown that a job match of a worker encourages positive employee performance, resulting in desirable associations, for example, higher employment fulfillment, lower turnover aim, and higher occupation execution (Bhat and Rainayee, 2019; Lee and Kim, 2020). Additionally, numerous investigations highlight the positive impact of workforce diversity on employee job performance, but the role of the person-job match is underexplored. Therefore, this study may be the primary examination to establish the connection between workforce diversity management and employee job performance by considering the person-job match and employee commitment as the independent mediating effect.

\section{Theoretical Implications}

First, prior workforce diversity management studies widely covered other perspectives of workforce diversity, such as surface-level diversity. This study, however, identifies the association between workforce diversity and employee job satisfaction by considering deep-level diversity management, which is related to the skills, abilities, and interests of employees (Li et al., 2020c). Second, departing from recent research results, such as Luu et al. (2019) and Park and Liang (2020), which reported a negative relationship between workforce diversity and employee job satisfaction, the results of the study provide evidence supporting the positive relationship between them, particularly in the context of pandemics. Third, a holistic research framework examining the relationship between workforce diversity management and employee job performance with the involvement of the person-job match, employee commitment, and structural empowerment remains underexplored. The current research fills the existing gap and extends the literature by considering the person-job match and employee commitment as mediators and structural empowerment as a moderator. Fourth, most prior studies by Cucina et al. (2018), Koellen (2019), Suharnomo et al. (2017), and Vanderschuere and Birdsall (2019) examined the relationship between workplace diversity management and employee job satisfaction in Western cultural settings (Zhuwao et al., 2019; Lee and Kim, 2020). This study, however, is based on an investigation in the telecommunications sector in China, which provides insights into the role of cultural issues in the relationship between workforce diversity management and employee job performance.

\section{Practical Implications}

Since the advent of human society, science and technology have made constant efforts toward effective communication to improve human-to-human interaction. With advancements in technology, the telecommunications sector has revolutionized over time. There has been a shift from localization to globalization, which is grounded in promoting connectivity with diverse human interactions (unique, surface, and deeplevel). Therefore, the main point to establish the connection between two parties from anywhere around the globe is centered on the telecommunications sector. Better establishment of local and global connections is a key reason for promoting workforce diversity, especially in the telecommunications sector. For instance, within China, there are many social and cultural dialects, so, for any organization, particularly within the telecommunications sector, to be representative of China as an entirety, workforce diversity is required to stay competitive and sustainable. As the world progresses in terms of technology adoption, new ways to connect, communicate, and create operational work opportunities for growth require a strong nexus between the telecommunications sector and workforce diversity. Therefore, this study provides meaningful implications for human resources managers for hiring new employees. This research explains the rationale that if there are people of different backgrounds working in a particular environment, there is room for variety, opportunities to interact at diverse levels, and stepping out of the box. Generally, effective communication is considered vital for better acquisition or delivery of tasks, ranging from small-scale to large-scale projects. This study provides empirical evidence for managers and researchers that there is a strong nexus among workforce diversity management, structural empowerment, person-job match, employee commitment, and employee job performance. Moreover, based on the policy of reform of China and opening up and the Belt and Road initiative, there is a need to promote the associations among workforce 
diversity management, structural empowerment, person-job match, employee commitment, and employee job performance at the individual, industrial, societal, and government levels to attain the objective of the community of the shared future. Besides this, it also provides implications for other sectors, such as the education sector, the health sector, the manufacturing sector, and both the public and private sectors. With respect to globalization and changing work dynamics, it is of importance to have better workforce diversity management to stay competitive and have better optimal utilization of limited resources and expansion of existing business operations.

\section{LIMITATIONS AND FUTURE RESEARCH DIRECTIONS}

The sample size of this study would likely be insufficient to generalize the results from existing examinations. This investigation utilized cross-sectional information, so it does not purport causal understandings. Nonetheless, future exploration might be benefited by breaking down longitudinal information to set up their relationship causality. A self-contained source in a solitary culture setting might provide the best information. Later, other social settings or studies can replicate this investigation by including various settings, for example, cross-cultures and other social settings, which would enrich the findings. Data were collected from a single type of sector (telecommunications) in China, which may limit the generalizability of our results. We cannot predict that various other sectors have a similar outcome based on these results. For instance, the assembling business is distinct, so employees may unexpectedly see various executives. Finally, further research can examine the effect of workforce diversity on other important factors, such as intergroup struggle, turnover intentions, and work-life balance, by taking a job match of a person as a mediator variable. A comparative study can be attempted from alternate viewpoints, for example, various nations and various ventures or distinctive work settings. Additionally, although the study was only conducted in China, culture and organizational/employee behavior vary significantly from place to place. To obtain a deeper understanding and new insights, future studies are encouraged to apply this model in the Western context with a large sample that encompasses various ages and places. Moreover, this study has checked the mediational effects individually rather than collectively as they were studied collectively in the past (Laschinger et al., 2006; Therasa and Vijayabanu, 2016; Hasan et al., 2021; Jyoti et al., 2021). Person job match and employee commitment are major influencing factors to influence the employee job performance. Therefore, we used both mediators as independent mediators. Looking into prior literature on human resource management and organizational behavior, the mediating roles of the person-job match and employee commitment in the relationship between diversity management and employee job performance are less studied. To investigate their respective mediating effect is the main research motivation of this study. However, there might be a relationship between the person-job match and employee commitment, which may result in a sequential mediating effect in the link between diversity management and performance, which is a strong recommendation for future research work.

\section{CONCLUSION}

Despite the constraints, this investigation provides significant insight that contributes to the existing theoretical foundations and helps managerial professionals through empirical verifications. The efficiency of a person is fundamental to ensure organizational competence in a dynamic world. Therefore, workforce diversity management is an important topic of exploration, as it primarily aims to promote a healthy environment in the present organization by considering workforce diversity as an asset rather than a liability. Previously, many organizations have suffered due to a lack of workforce diversity management. The linkage between workforce diversity management also promotes employee commitment based on employee job performance, which is a helpful apparatus to lessen working environment negativism. No study has examined the immediate impact of workforce diversity management on employee job performance and the mediating roles of the person-job match and employee commitment and moderating effect of structural empowerment holistically. For this study, data are collected from the telecommunications sector, which holds significance, as explained above, because the Chinese Belt and Road Initiative require better network and telecommunications connectivity across diverse countries, which is the key to ensuring a shared global future. After data collection, the emerging econometric technique of structural equation modeling (SEM) was used to generate empirical evidence. The study findings are aligned with the theoretical foundations previously established by eminent scholars, and the empirical evidence also supports the economic rationale. Thus, this study provides new food of thought for deeper exploration and comparative analysis across sectors and regions.

\section{DATA AVAILABILITY STATEMENT}

The raw data supporting the conclusions of this article will be made available by the authors, without undue reservation.

\section{ETHICS STATEMENT}

The Jiangsu University review board exempted the research from ethical approval as it was a survey-based study. Informed consent was obtained from all the subjects involved in the study while collecting the data through an online questionnaire.

\section{AUTHOR CONTRIBUTIONS}

ZL and MO contributed to developing the theoretical framework, data analysis, and overall writing of the manuscript. SF and UA contributed to data collection, data analysis and the editing and the organization of the manuscript. All authors contributed to the article and approved the submitted version. 


\section{REFERENCES}

Aceto, G., Persico, V., and Pescape, A. (2019). A survey on information and communication technologies for Industry 4.0: state-of-the-art, taxonomies, perspectives, and challenges. IEEE Commun. Surveys Tutorials 21, 3467-3501. doi: 10.1109/COMST.2019.2938259

Akinola, M., Martin, A. E., and Phillips, K. W. (2018). To delegate or not to delegate: gender differences in affective associations and behavioral responses to delegation. Acad. Manage. J. 61, 1467-1491. doi: 10.5465/amj.2016.0662

Al Zefeiti, S. M. B., and Mohamad, N. A. (2017). The Influence of organizational commitment on Omani public employees' work performance. Int. Rev. Manage. Market. 7, 151-160. Available online at: https://econjournals.com/ index.php

Amor, A. M., Vázquez, J. P. A., and Faíña, J. A. (2020). Transformational leadership and work engagement: exploring the mediating role of structural empowerment. Euro. Manage. J. 38, 169-178. doi: 10.1016/j.emj.2019.06.007

Andrew, A. (2017). Employees' commitment and its impact on organizational performance. Asian J. Econ. Business Account. 5, 1-13. doi: $10.9734 / \mathrm{AJEBA} / 2017 / 38396$

Arslan Yürümezoglu, H., and Kocaman, G. (2019). Structural empowerment, workplace incivility, nurses' intentions to leave their organisation and profession: a path analysis. J. Nurs. Manag. 27, 732-739. doi: $10.1111 /$ jonm. 12751

Ashikali, T., and Groeneveld, S. (2015). Diversity management in public organizations and itseffect employees' affective commitment: the role of transformational leadership andthe inclusiveness of the organizational culture. Rev. Public Personnel Administr. 35, 146-168. doi: 10.1177/0734371X13511088

Asif, M., Jameel, A., Hussain, A., Hwang, J., and Sahito, N. (2019). Linking transformational leadership with nurse-assessed adverse patient outcomes and the quality of care: assessing the role of job satisfaction and structural empowerment. Int. J. Environ. Res. Public Health 16:2381. doi: 10.3390/ijerph16132381

Bagozzi, R. P., and Yi, Y. (1988). On the evaluation of structural equation models. J. Acad. Market. Sci. 16, 74-94. doi: 10.1007/BF02723327

Bassett-Jones, N. (2005). The paradox of diversity management, creativity and innovation. Creativity Innov. Manage. 14, 169-175. doi: 10.1111/j.1467-8691.00337.x

Baytos, L. (1992). Launching successful diversity initiatives. HR Magazine 373, 91-99.

Bhat, Z. H., and Rainayee, R. A. (2019). Examining the mediating role of personjob fit in the relationship between training and performance: a civil servant perspective. Global Business Rev. 20, 529-548. doi: 10.1177/0972150917743377

Brimhall, K. C. (2019). Inclusion and commitment as key pathways between leadership and nonprofit performance. Nonprofit Manageme. Leadership 30, 31-49. doi: $10.1002 / \mathrm{nml} .21368$

Bunderson, J. S., and Sutcliffe, K. M. (2002). Comparing alternative conceptualizations of functional diversity in management teams: process and performance effects. Acad. Manage. J. 45, 875-893. doi: 10.2307/3069319

Byza, O. A., Dörr, S. L., Schuh, S. C., and Maier, G. W. (2019). When leaders and followers match: the impact of objective value congruence, value extremity, and empowerment on employee commitment and job satisfaction. J. Business Ethics 158, 1097-1112. doi: 10.1007/s10551-017-3748-3

Casper, W. J., Wayne, J. H., and Manegold, J. G. (2013). Who will we recruit? Targeting deep-and surface-level diversity with human resource policy advertising. Human Resource Manage. 52, 311-332. doi: 10.1002/hrm.21530

Cesário, F., and Chambel, M. J. (2017). Linking organizational commitment and work engagement to employee performance. Knowl. Process Manage. 24, 152-158. doi: 10.1002/kpm.1542

Chin, W. W. (1998). The partial least squares approach to structural equation modeling. Modern Methods Business Res. 295, 295-336.

Cho, S., Kim, A., and Mor Barak, M. E. (2017). Does diversity matter? Exploring workforce diversity, diversity management, and organizational performance in social enterprises. Asian Soc. Work Policy Rev. 11, 193-204. doi: $10.1111 /$ aswp. 12125

Choi, S., and Rainey, H. G. (2010). Managing diversity in US federal agencies: effects of diversity and diversity management on employee perceptions of organizational performance. Public Adm. Rev. 70, 109-121. doi: 10.1111/j.1540-6210.2009.02115.x
Choi, S. L., Goh, C. F., Adam, M. B. H., and Tan, O. K. (2016). Transformational leadership, empowerment, and job satisfaction: the mediating role of employee empowerment. Hum. Resour. Health 14:73. doi: 10.1186/s12960-016-0171-2

Chordiya, R., Sabharwal, M., and Goodman, D. (2017). Affective organizational commitment and job satisfaction: a cross-national comparative study. Public Adm. 95, 178-195. doi: 10.1111/padm.12306

Choudhary, N., Naqshbandi, M. M., Philip, P., and Kumar, R. (2017). Employee job performance. J. Manage. Dev. doi: 10.1108/JMD-10-2016-0195

Chun, L., Tham, J., and Azam, S. F. (2019). Corporate competence determining factors in china telecom industry in achieving customer satisfaction. Euro. J. Manage. Market. Stud. 4, 75-101. doi: 10.46827/ejmms.v0i0.684

Collins, C. J. (2021). Expanding the resource based view model of strategic human resource management. Int. J. Human Resource Manage. 32, 331-358. doi: 10.1080/09585192.2019.1711442

Cooke, F. L., and Saini, D. S. (2010). Diversity management in India: a study of organizations in different ownership forms and industrial sectors. Hum. Resour. Manage. 49, 477-500. doi: 10.1002/hrm.20360

Cucina, J. M., Byle, K. A., Martin, N. R., Peyton, S. T., and Gast, I. F. (2018). Generational differences in workplace attitudes and job satisfaction. J. Managerial Psychol. 33, 246-264. doi: 10.1108/JMP-03-2017-0115

Dahinten, V., Lee, S., and MacPhee, M. (2016). Disentangling the relationships between staff nurses' workplace empowerment and job satisfaction. J. Nurs. Manag. 24:10601070. doi: 10.1111/jonm.12407

Delmas, M. A., and Pekovic, S. (2018). Organizational configurations for sustainability and employee productivity: a qualitative comparative analysis approach. Business Soc. 57, 216-251. doi: 10.1177/0007650317703648

Edquist, H., Goodridge, P., Haskel, J., Li, X., and Lindquist, E. (2018). How important are mobile broadband networks for the global economic development? Information Econ. Policy 45, 16-29. doi: 10.1016/j.infoecopol.2018.10.001

Fornell, C., and Larcker, D. F. (1981). Evaluating structural equation models with unobservable variables and measurement error. J. Market. Res. 18:3950. doi: $10.2307 / 3151312$

Garg, N. (2017). Workplace spirituality and employee well-being: an empirical exploration. J. Human Values 23, 129-147. doi: 10.1177/0971685816689741

Gilbert, J., Stead, B. A., and Ivancevich, J. (1999). Diversity management: a new organizational paradigm. J. Business Ethics 21, 61-76. doi: 10.1023/A:1005907602028

Gomez, L., and Bernet, P. (2019). Diversity improves performance and outcomes. J. Natl. Med. Assoc. 111, 383-392. doi: 10.1016/j.jnma.2019.01.006

Goswami, S., and Goswami, B. K. (2018). Exploring the relationship between workforce diversity, inclusion and employee engagement. Drishtikon Manage. J. 9, 65-89.

Gouldner, A. W. (1960). The norm of reciprocity: a preliminary statement. Am. Sociol. Rev. 25, 161-178. doi: 10.2307/2092623

Hair, J. F. Jr., Hult, G. T. M., Ringle, C., and Sarstedt, M. (2016). A Primer on Partial Least Squares Structural Equation Modeling (PLS-SEM). Thousand Oaks, CA: Sage Publications.

Harman, D. (1967). A single factor test of common method variance. J. Psychol. 35, 359-378.

Hasan, T., Jawaad, M., and Butt, I. (2021). The influence of person-job fit, worklife balance, and work conditions on organizational commitment: investigating the mediation of job satisfaction in the private sector of the emerging market. Sustainability 13:6622. doi: 10.3390/su13126622

Heckscher, C. (1994). "Defining the post-bureaucratic type," in The PostBureaucratic Organization, eds C. Heckscher and A. Donnellon (Thousand Oaks, CA: Sage), 14-62.

Hofmann, V., and Stokburger-Sauer, N. E. (2017). The impact of emotional labor on employees' work-life balance perception and commitment: a study in the hospitality industry. Int. J. Hospitality Manage. 65, 47-58. doi: $10.1016 /$ j.ijhm.2017.06.003

Horwitz, S. K., and Horwitz, I. B. (2007). The effects of team diversity on team outcomes: a meta- analytic review of team demography. J. Manage. 33, 987-1015. doi: 10.1177/0149206307308587

Hu, L. T., and Bentler, P. M. (1999). Cutoff criteria for fit indexes in covariance structure analysis: conventional criteria versus new alternatives. Struct. Equation Model. Multidisciplinary J. 6, 1-55. doi: 10.1080/107055199095 40118 
Huang, W., Yuan, C., and Li, M. (2019). Person-job fit and innovation behavior: roles of job involvement and career commitment. Front. Psychol. 10:1134. doi: 10.3389/fpsyg.2019.01134

Ibidunni, A. S., Falola, H. O., Ibidunni, O. M., Salau, O. P., Olokundun, M. A., Borishade, T. T., et al. (2018). Workforce diversity among public healthcare workers in Nigeria: implications on job satisfaction and organisational commitment. Data Brief 18, 1047-1053. doi: 10.1016/j.dib.2018.03.127

Jaiswal, R., Raychaudhuri, P. S., Rahman, N. M., and Khan, J. A. (2019). Exploring organizational commitment and its implications for HRM: a review and critique of literature. Asian J. Multidimensional Res. 8, 39-52. doi: 10.5958/2278-4853.2019.00216.7

Joshi, A., and Jackson, S. E. (2003). "Managing workforce diversity to enhance cooperation in organizations," in International Handbook of Organizational Teamwork Cooperative Working, eds M. A. West, D. Tjosvold, and K. G. Smith (John Wiley \& Sons Limited), 277-296.

Ju, B., and Li, J. (2019). Exploring the impact of training, job tenure, and educationjob and skills-job matches on employee turnover intention. Euro. J. Training Dev. 43, 214-231. doi: 10.1108/EJTD-05-2018-0045

Jyoti, J., Sharma, P., Kour, S., and Kour, H. (2021). The role of job involvement and career commitment between person-job fit and organizational commitment: a study of higher education sector. Int. J. Educ. Manage. 35, 109-130. doi: 10.1108/IJEM-06-2019-0205

Kanter, R. M. (1993). Men and Women of the Corporation, 2nd Edn. New York, NY: Basic Books.

Kerga, A. B., and Asefa, A. (2018). The effect of workforce diversity on employee performance (the case of ethio-telecom south west Addis Ababa zone). Asian J. Econ. Business Account. 8, 1-27. doi: 10.9734/AJEBA/2018/43760

Klein, H. J., Cooper, J. T., Molloy, J. C., and Swanson, J. A. (2014). The assessment of commitment: advantages of a unidimensional, target-free approach. J. Appl. Psychol. 99:222. doi: 10.1037/a0034751

Kniffin, K. M., Narayanan, J., Anseel, F., Antonakis, J., Ashford, S. P., Bakker, A. B., et al. (2021). COVID-19 and the workplace: implications, issues, and insights for future research and action. Am. Psychol. 76:63. doi: 10.1037/amp0000716

Koellen, T. (2019). Diversity management: a critical review and agenda for the future. J. Manage. Inquiry. 30, 259-272. doi: 10.1177/1056492619868025

Kundu, S. C., and Mor, A. (2017). Workforce diversity and organizational performance: a study of IT industry in India. Employee Relations 39, 160-183. doi: 10.1108/ER-06-2015-0114

Laschinger, H. K. S., Wong, C. A., and Greco, P. (2006). The impact of staff nurse empowerment on person-job fit and work engagement/burnout. Nurs. Adm. Q. 30, 358-367. doi: 10.1097/00006216-200610000-00008

Lau, P. Y. Y., Tong, J. L. T., Lien, B. Y.-H., Hsu, Y.-C., and Chong, C. L. (2017). Ethical work climate, employee commitment and proactive customer service performance: test of the mediating effects of organizational politics. J. Retailing Consumer Serv. 35, 20-26. doi: 10.1016/j.jretconser.2016.11.004

Leach, D. J., Wall, T. D., and Jackson, P. R. (2003). The effect of empowerment on job knowledge: an empirical test involving operators of complex technology. J. Occup. Organ. Psychol. 76, 27-52. doi: 10.1348/096317903321208871

Lee, H. W., and Kim, E. (2020). Workforce diversity and firm performance: relational coordination as a mediator and structural empowerment and multisource feedback as moderators. Hum. Resour. Manage. 59, 5-23. doi: $10.1002 / \mathrm{hrm} .21970$

Lee, Y., and Sabharwal, M. (2016). Education-job match, salary, and job satisfaction across the public, non-profit, and for-profit sectors: survey of recent college graduates. Public Manage. Rev. 18, 40-64. doi: 10.1080/14719037.2014.957342

Li, C., Murad, M., Shahzad, F., Khan, M. A. S., and Ashraf, S. F. (2020a). Dark tetrad personality traits and counterproductive work behavior among doctors in Pakistan. Int. J. Health Plann. Manage. 10, 1-16. doi: 10.1002/hpm.3025

Li, C., Murad, M., Shahzad, F., Khan, M. A. S., Ashraf, S. F., and Dogbe, C. S. K. (2020b). Entrepreneurial passion to entrepreneurial behavior: role of entrepreneurial alertness, entrepreneurial self-efficacy and proactive personality. Front. Psychol. 11:1611. doi: 10.3389/fpsyg.2020.01611

Li, J., Roessler, R. T., Rumrill Jr, P. D., and Ahmed, E. R. (2017). Factors influencing job satisfaction for employed adults with multiple sclerosis. Rehabil. Couns. Bull. 61, 28-40. doi: 10.1177/0034355216662616

Li, W., Wang, X., Haque, M. J., Shafique, M. N., and Nawaz, M. Z. (2020c). Impact of workforce diversity management on employees' outcomes: testing the mediating role of a person's job match. SAGE Open 10:2158244020903402. doi: $10.1177 / 2158244020903402$

Luu, T. T., Rowley, C., and Vo, T. T. (2019). Addressing employee diversity to foster their work engagement. J. Bus. Res. 95, 303-315. doi: 10.1016/j.jbusres.2018.08.017

Maan, A. T., Abid, G., Butt, T. H., Ashfaq, F., and Ahmed, S. (2020). Perceived organizational support and job satisfaction: a moderated mediation model of proactive personality and psychological empowerment. Future Business J. 6, 1-12. doi: 10.1186/s43093-020-00027-8

Maden, C. (2014). Impact of fit, involvement, and tenure on job satisfaction and turnover intention. Service Industries J. 34, 1113-1133. doi: 10.1080/02642069.2014.939644

Madera, J. M. (2013). Best practices in diversity management in customer service organizations: an investigation of top companies cited by Diversity Inc. Sage J. 54, 124-135. doi: 10.1177/1938965513475526

Mathieu, J. E., Gilson, L. L., and Ruddy, T. M. (2006). Empowerment and team effectiveness: an empirical test of an integrated model. J. Appl. Psychol. 91:97. doi: 10.1037/0021-9010.91.1.97

Medeiros, E. S. (2009). China's International Behavior: Activism, Opportunism, and Diversification, Vol. 850. Santa Monica, CA: Rand Corporation.

Meyer, J. P., Becker, T. E., and Vandenberghe, C. (2004). Employee commitment and motivation: a conceptual analysis and integrative model. J. Appl. Psychol. 89:991. doi: 10.1037/0021-9010.89.6.991

Meyer, J. P., Stanley, L. J., and Parfyonova, N. M. (2012). Employee commitment in context: the nature and implication of commitment profiles. J. Vocat. Behav. 80, 1-16. doi: 10.1016/j.jvb.2011.07.002

Mills, P. K., and Ungson, G. R. (2003). Reassessing the limits of structural empowerment: organizational constitution and trust as controls. Acad. Manage. Rev. 28, 143-153. doi: 10.5465/amr.2003.8925254

Mintzberg, H. (1979). The Structuring of Organization: A Synthesis of the Research. Englewood Cliffs, NJ: Prentice-Hall.

Moon, K.-K., and Christensen, R. K. (2020). Realizing the performance benefits of workforce diversity in the US Federal Government: the moderating role of diversity climate. Public Pers. Manage. 49, 141-165. doi: $10.1177 / 0091026019848458$

Mor Barak, M. E. (2015). Inclusion is the key to diversity management, but what is inclusion? Hum. Serv. Org. Manage. Leadership Governance 39, 83-88. doi: 10.1080/23303131.2015.1035599

Mor Barak, M. E., Lizano, E. L., Kim, A., Duan, L., Rhee, M.-K., Hsiao, H.-Y., et al. (2016). The promise of diversity management for climate of inclusion: a state-of-the-art review and meta-analysis. Hum. Serv. Org. Manage. Leadership Governance 40, 305-333. doi: 10.1080/23303131.2016. 1138915

Mulki, J. P., Jaramillo, F., and Locander, W. B. (2006). Emotional exhaustion and organizational deviance: can the right job and a leader's style make a difference? J. Bus. Res. 59, 1222-1230. doi: 10.1016/j.jbusres.2006.09.001

Ng, E. S., and Sears, G. J. (2012). CEO leadership styles and the implementation of organizational diversity practices: moderating effects of social values and age. $J$. Business Ethics 105, 41-52. doi: 10.1007/s10551-011-0933-7

Nunally, J. C., and Bernstein, I. H. (1978). Psychometric Theory. New York, NY: McGraw-Hill.

Ozcelik, H., and Barsade, S. G. (2018). No employee an island: workplace loneliness and job performance. Acad. Manage. J. 61, 2343-2366. doi: 10.5465/amj.2015.1066

Paglierani, P., Neokosmidis, I., Rokkas, T., Meani, C., Nasr, K. M., Moessner, K., et al. (2020). Techno-economic analysis of $5 \mathrm{G}$ immersive media services in cloud-enabled small cell networks: the neutral host business model: providing techno-economic guidelines for the successful provision of 5G innovative services in small cell networks. Trans. Emerg. Telecommun. Technol. 31:e3746. doi: $10.1002 /$ ett.3746

Park, S., and Liang, J. (2020). Merit, diversity, and performance: does diversity management moderate the effect of merit principles on governmental performance? Public Pers. Manage. 49, 83-110. doi: 10.1177/00910260198 48459

Podsakoff, P. M., MacKenzie, S. B., Lee, J.-Y., and Podsakoff, N. P. (2003). Common method biases in behavioral research: a critical review of the literature and recommended remedies. J. Appl. Psychol. 88:879. doi: 10.1037/0021-9010.88.5.879 
Preacher, K. J., and Hayes, A. F. (2008). Asymptotic and resampling strategies for assessing and comparing indirect effects in multiple mediator models. Behav. Res. Methods 40, 879-891. doi: 10.3758/BRM.40.3.879

Prieto, L. C., Phipps, S. T., and Osiri, J. K. (2009). Linking workplace diversity to organizational performance: a conceptual framework. J. Diversity Manage. 4, 13-22. doi: $10.19030 / j d m . v 4 i 4.4966$

Putri, E. R., and Djastuti, I. (2019). Structural empowerment and service-oriented organizational citizenship behavior: the mediating roles of innovativeness and job satisfaction. Quality Access Success 20, 112-117.

Ramdhani, A., Ramdhani, M. A., and Ainissyifa, H. (2017). Conceptual framework of corporate culture influenced on employees commitment to organization. Int. Business Manage. 11, 826-830. doi: 10.36478/ibm.2017.826.830

Rizwan, M., Khan, M. N., Nadeem, B., and Abbas, Q. (2016). The impact of workforce diversity towards employee performance: evidence from banking sector of Pakistan. Am. J. Market. Res. 2, 53-60. Available online at: https:// www.oapub.org/soc/

Sengers, J. H., Abma, F. I., Ståhl, C., and Brouwer, S. (2020). Work capacity assessments and efforts to achieve a job match for claimants in a social security setting: an international inventory. Disabil. Rehabil. 1-10. doi: 10.1080/09638288.2020.1810787

Shao, D., Zhou, E., Gao, P., Long, L., and Xiong, J. (2019). Double-edged effects of socially responsible human resource management on employee task performance and organizational citizenship behavior: mediating by role ambiguity and moderating by prosocial motivation. Sustainability 11:2271. doi: 10.3390/su11082271

Snowdon, D. A., Storr, B., Davis, A., Taylor, N. F., and Williams, C. M. (2020). The effect of delegation of therapy to allied health assistants on patient and organisational outcomes: a systematic review and meta-analysis. BMC Health Serv. Res. 20, 1-16. doi: 10.1186/s12913-020-05312-4

Spreitzer, G. M. (2008). Taking stock: a review of more than twenty years of research on empowerment at work. Handbook Org. Behav. 1, 54-72. doi: $10.4135 / 9781849200448 . n 4$

Spreitzer, G. M., and Doneson, D. (2005). Musings on the past and future of employee empowerment. Handbook Org. Dev. 4, 5-10. Available online at: https://www.researchgate.net/profile/Gretchen-Spreitzer/ publication/255649410_Musings_on_the_Past_and_Future_of_Employee Empowerment/links/54b8f8b20cf269d8cbf72813/Musings-on-the-Past-andFuture-of-Employee-Empowerment.pdf

Suharnomo, A. Y., Wahyudi, S., and Wikaningrum, T. (2017). A systematic literature review of managing workplace diversity for sustaining organizational competitive advantage. J. Mech. Eng. Technol. 8, 398-406. Available online at: http://www.iaeme.com/IJMET/issues.asp?JType=IJMET\&VType= 8\&IType $=12$

Sylva, H., Mol, S. T., Den Hartog, D. N., and Dorenbosch, L. (2019). Person-job fit and proactive career behaviour: a dynamic approach. Euro. J. Work Org. Psychol. 28, 631-645. doi: 10.1080/1359432X.2019.1580309

Teo, S. T., Bentley, T., and Nguyen, D. (2020). Psychosocial work environment, work engagement, and employee commitment: a moderated, mediation model. Int. J. Hospitality Manage. 88:102415. doi: 10.1016/j.ijhm.2019.102415

Therasa, C., and Vijayabanu, C. (2016). Person-job fi $t$ and the work commitment of IT Personnel. J. Human Growth Dev. 26, 218-227. doi: 10.7322/jhgd.119277

Vanderschuere, M., and Birdsall, C. (2019). Can diversity management improve job satisfaction military veterans in the federal government? Am. Rev. Public Administr. 49, 116-127. doi: 10.1177/0275074018783005

Wei, Y. D., Wu, Y., Liao, F. H., and Zhang, L. (2020). Regional inequality, spatial polarization and place mobility in provincial China: a case study of Jiangsu province. Appl. Geogr. 124:102296. doi: 10.1016/j.apgeog.2020.102296
Wernerfelt, B. (1984). A resource-based view of the firm. Strategic Manage. J. 5, 171-180. doi: 10.1002/smj.4250050207

Wu, T.-J., Gao, J.-Y., Wang, L.-Y., and Yuan, K.-S. (2020). Exploring links between polychronicity and job performance from the person-environment fit perspective-the mediating role of well-being. Int. J. Environ. Res. Public Health 17:3711. doi: 10.3390/ijerph17103711

Yadav, A., and Katiyar, D. (2017). Workforce diversity and individual differences: implications for employee engagement. J. Commerce Manage. Stud. 8:7. doi: $10.18843 / \mathrm{ijcms} / \mathrm{v} 8 \mathrm{i} 3 / 02$

Yousef, D. A. (2000). Organizational commitment: a mediator of the relationships of leadership behavior with job satisfaction and performance in a nonwestern country. J. Managerial Psychol. 15, 6-24. doi: 10.1108/026839400103 05270

Yu, M. C., Mai, Q., Tsai, S. B., and Dai, Y. (2018). An empirical study on the organizational trust, employee-organization relationship and innovative behavior from the integrated perspective of social exchange and organizational sustainability. Sustainability 10:864. doi: 10.3390/su100 30864

Zagenczyk, T. J., Purvis, R. L., Cruz, K. S., Thoroughgood, C. N., and Sawyer, K. B. (2020). Context and social exchange: perceived ethical climate strengthens the relationships between perceived organizational support and organizational identification and commitment. Int. J. Human Resource Manage. 1-20. doi: 10.1080/09585192.2019.1706618

Zhang, X. (2021). Broadband and economic growth in China: an empirical study during the COVID-19 pandemic period. Telematics Informatics 58:101533. doi: 10.1016/j.tele.2020.101533

Zhang, X., Ye, H., and Li, Y. (2018). Correlates of structural empowerment, psychological empowerment and emotional exhaustion among registered nurses: a meta-analysis. Appl. Nurs. Res. 42, 9-16. doi: 10.1016/j.apnr.2018.04.006

Zhuwao, S., Ngirande, H., Ndlovu, W., and Setati, S. T. (2019). Gender diversity, ethnic diversity, and employee performance in a South African higher education institution. SA J. Human Resource Manage. 17, 1-8. doi: $10.4102 /$ sajhrm.v17i0.1061

Zongze, R. (2018). Building a community with a shared future: meliorating the era of strategic opportunity in China. China Int'l Stud. 69:5. Available online at: https://heinonline.org/HOL/LandingPage?handle=hein.journals/chintersd69\& $\operatorname{div}=4 \&$ id $=\&$ page $=$

Conflict of Interest: The authors declare that the research was conducted in the absence of any commercial or financial relationships that could be construed as a potential conflict of interest.

Publisher's Note: All claims expressed in this article are solely those of the authors and do not necessarily represent those of their affiliated organizations, or those of the publisher, the editors and the reviewers. Any product that may be evaluated in this article, or claim that may be made by its manufacturer, is not guaranteed or endorsed by the publisher.

Copyright (c) 2021 Li, Oljaca, Firdousi and Akram. This is an open-access article distributed under the terms of the Creative Commons Attribution License (CC BY). The use, distribution or reproduction in other forums is permitted, provided the original author(s) and the copyright owner(s) are credited and that the original publication in this journal is cited, in accordance with accepted academic practice. No use, distribution or reproduction is permitted which does not comply with these terms. 


\section{APPENDIX A}

All the items are measured using five-point Likert scales, ranging from 1 , strongly disagree, to 5 , strongly agree.

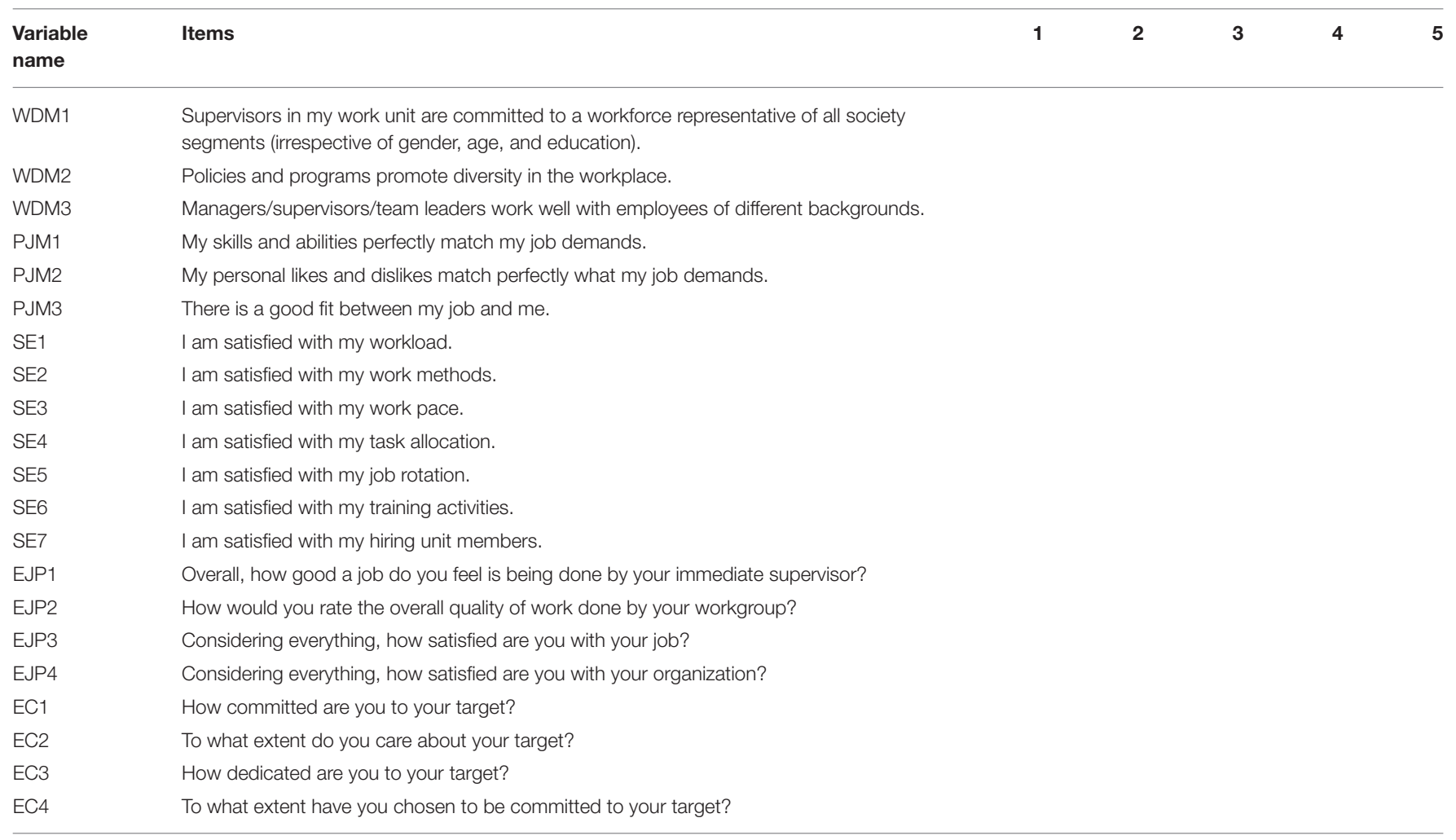

